\title{
Particle Size Distribution and Optical Volume Scattering Function in the Mid and Upper Water Column of Optically Deep Coastal Regions: Transport from the Bottom Boundary Layer
}

\author{
Y. C. Agrawal \\ Sequoia Scientific, Inc., \\ Westpark Technology Center \\ 15317, NE $90^{\text {th }}$ St., \\ Redmond WA 98052 \\ phone: (425) 867-2464 fax: (425) 867-5506 email: yogi@sequoiasci.com \\ Contract No. N0001402C0123 \\ http://www.onr.navy.mil/sci_tech/ocean/onrpgahj.htm
}

\section{LONG-TERM GOALS}

My long-term goal is to understand the processes that contribute to the establishment of the vertical structure of size-distribution of suspended sediments and sediment concentration, with the bottom boundary layer acting as the principal source.

\section{OBJECTIVES}

The source for particulates in shallow water (though optically deep) is the bottom boundary layer, and subsequent diffusion and advection by processes that include upwelling. My objective in this program is to examine the relative importance of these processes by simultaneously observing the vertical distribution of particles, and the advective-diffusive mixing processes. Simultaneously, the instruments that measure particle size-distribution will also provide measurements of the small-angle volume scattering function of water from 0.1 to 20 degrees, at the wavelength of the diode lasers, 0.67 micron.

\section{APPROACH}

Measurements of suspended sediments (size distribution and concentration) were carried out throughout the water column using a LISST-100 instrument on a profiler. In addition, LISST-100 instruments measured the same parameters from a bottom-mounted tripod. The settling velocity distribution of the particles - a key parameter that establishes the diffusion-settling balance - was measured using a LISST-ST instrument. These constitute the set for sediments. The velocity field was measured with a set of velocimeters mounted on the tripod by Dr. John Trowbridge, WHOI. All sensors were synchronized. Data were stored on-board the instruments and was transmitted to shore . The joint analysis of the measurements is continuing at the time of this writing, with early publications and presentations having appeared in unrefereed publications. 


\section{Report Documentation Page}

Form Approved

OMB No. 0704-0188

Public reporting burden for the collection of information is estimated to average 1 hour per response, including the time for reviewing instructions, searching existing data sources, gathering and maintaining the data needed, and completing and reviewing the collection of information. Send comments regarding this burden estimate or any other aspect of this collection of information,

including suggestions for reducing this burden, to Washington Headquarters Services, Directorate for Information Operations and Reports, 1215 Jefferson Davis Highway, Suite 1204, Arlington

VA 22202-4302. Respondents should be aware that notwithstanding any other provision of law, no person shall be subject to a penalty for failing to comply with a collection of information if it

does not display a currently valid OMB control number.

1. REPORT DATE

30 SEP 2003

2. REPORT TYPE

3. DATES COVERED

00-00-2003 to 00-00-2003

4. TITLE AND SUBTITLE

Particle Size Distribution and Optical Volume Scattering Function in the Mid and Upper Water Column of Optically Deep Coastal Regions:

Transport from the Bottom Boundary Layer

CONTRACT NUMBER

6. $\operatorname{AUTHOR}(\mathrm{S})$

7. PERFORMING ORGANIZATION NAME(S) AND ADDRESS(ES)

Sequoia Scientific, Inc.,,Westpark Technology Center,15317, NE 90th

St.,,Redmond,,WA, 98052

9. SPONSORING/MONITORING AGENCY NAME(S) AND ADDRESS(ES)

10. SPONSOR/MONITOR'S ACRONYM(S)

11. SPONSOR/MONITOR'S REPORT

NUMBER(S)

12. DISTRIBUTION/AVAILABILITY STATEMENT

Approved for public release; distribution unlimited

13. SUPPLEMENTARY NOTES

14. ABSTRACT

15. SUBJECT TERMS

16. SECURITY CLASSIFICATION OF:

a. REPORT

b. ABSTRACT

unclassified

unclassified

c. THIS PAGE

unclassified
17. LIMITATION OF ABSTRACT

Same as

Report (SAR)
18. NUMBER OF PAGES

5 19a. NAME OF

RESPONSIBLE PERSON

5d. PROJECT NUMBER

5e. TASK NUMBER

8. PERFORMING ORGANIZATION

REPORT NUMBER

Standard Form 298 (Rev. 8-98) Prescribed by ANSI Std Z39-18 


\section{WORK COMPLETED}

During the first year of this program (FY1999), data were obtained from a single LISST-100 instrument mounted on a vertical profiler at the LEO-15 site.

In the second year, all instruments were completed for deployment and a summer deployment occurred. A tripod carrying a LISST-100, one LISST-ST and an MSCAT instrument was deployed at the LEO-15 site. In addition, the LISST-100 on the vertical profiler was re-deployed.

In the third and final year, all instruments were redeployed, operating in the autonomous mode. Full data were recovered from all instruments.

As a consequence, we have gathered data on the size-distribution, concentration, and settling velocity distribution of suspended particles, measured both throughout the water column, and more extensively in the bottom 2 meters, from a tripod. As a consequence, $(i)$ The volume scattering function (VSF) of the water column has been studied from the data received from the profiling LISST-100. This has been reported in the Ocean Optics XVI conference Proceedings; (ii) Settling velocity spectra have been obtained from the LISST-ST data. Results support hypotheses of fractal nature of the larger particles; and (iii) The detailed analysis of size-distribution in the bottom boundary layer is ongoing. These will be combined with the bottom hydrodynamic forcing data of Dr. Trowbridge in the remaining final year of this program.

\section{RESULTS}

Volume Scattering Function: We have displayed bottom boundary layer data in earlier report. This year, we stress the observed large variability in the volume scattering function in the water column.

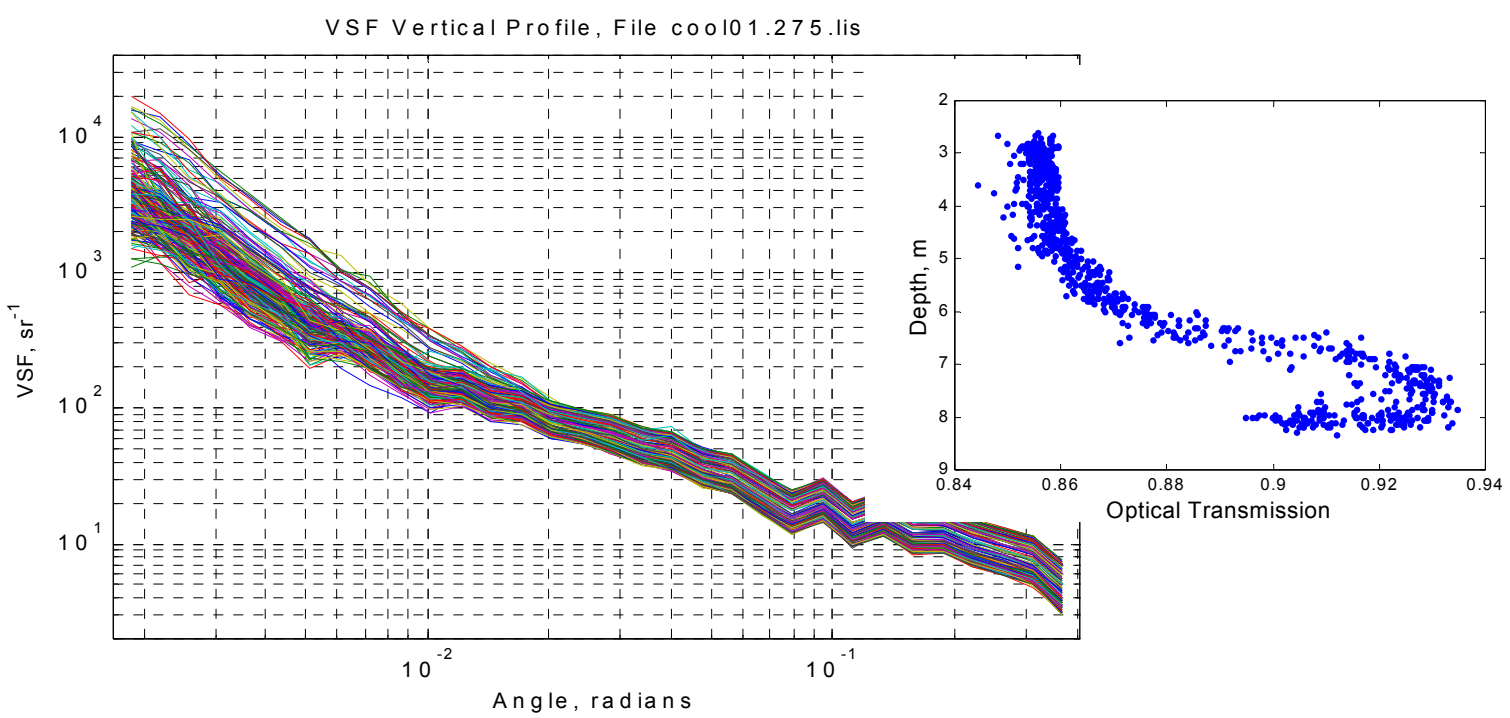

Fig.1: In a single vertical profile, variability of VSF magnitude is seen principally at small angles (left), in the event of a turbid layer overlying bottom water (optical transmission profile, insert) 
In all, 400 vertical profiles of the LISST-100 have been analyzed to date. The data show a wide variability in the magnitude and shape of the volume scattering function within the water column, but still

excluding the bottom nepheloid layer. The greatest variability in a single profile is generally seen to be at the smallest angles, representing the availability of larger particles to different parts of the water column (generally lower column). However, when different water masses overlie each other, the variability at the larger angles $\left(>2^{0}\right)$ is also large, having been established by the fine particle content of the water masse.

The link between suspended particle concentration and size-distribution asserts that as the particle dynamics respond to the various forcing functions, so should the measured volume scattering function. This has been clearly established.

A clear conclusion of this work is that it is time to abandon notions of canonical forms of the volume scattering functions that have been in use since Petzold's ground-breaking measurements. The data from our measurements show a variability in the VSF of several orders of magnitude in time, and in space.

Scattering by Random Shaped Natural Particles: In a broadly significant research project, we are continuing the study of the small-angle scattering particles of random shaped marine particles. This empirical study has direct bearing on the inversion of multi-angle scattering observed by the LISST instruments, and is of fundamental interest in all studies of light scattering. Some results were presented at the Ocean Sciences (2002) conference in Honolulu. The most serious challenge to this study is the sorting of particles by a defined 'size'. Using novel techniques that exploit the turbulencesuppressing qualities of density-stratified water columns, we have achieved a qualitative understanding of the light scattering properties. Further progress requires the collection of measurable quantities of size-sorted particles to determine the absolute scattering cross-sections vs. size. This remains an elusive goal as of this writing.

\section{IMPACT/APPLICATION}

The work is in early stages of publications. However, research on the fractal nature of particles will be boosted by these studies, in addition to information on the variability of VSF in the water column.

\section{TRANSITIONS}

None.

\section{RELATED PROJECTS}

1 - Small-Angle Scattering Properties of Natural Particles:- Spurred by observations of differences in calibrations of sediment sensors for spheres vs. natural particles, we have completed the first phase of empirically characterization of the very small-angle scattering properties of these particles. Using a specially constructed stratified settling column, we have characterized the counterpart to Mie scattering properties for narrow size classes. This work is in preparation for publication. 
2 - The Design of shaped focal plane detectors for sediment property measurements:- We have noted elsewhere the design and use of a so called 'comet' shaped detector in use in our instrument LISST-25. The shape of this comet is designed to that the output of this focal plane detector is directly proportional to the concentration of suspended sediment concentration over a broad 200:1 size range. In contrast, prior technology suffered a factor of 200 error due to size and a further error of factor 10 due to color changes while monitoring sediments. The new comet is based on diffraction theory so that it is a true sediment sensor, immune to calibration changes due to composition.

Subsequent to the design of the original comet, an additional shape was found that measured a subrange of coarse particles only ( $63<$ diameter $<500$ microns). These shapes produced the volumetric concentration, and from the particle area concentration inferred from another comet shape, a Sauter Mean Diameter was derived for the sub-range also.

Most recently, yet another shape of the comet detector has been found that permits observation of the true mean diameter of the full range of sizes. The associated sub-range detector for $63<$ diameter $<500$ microns has also been designed.

These fully general focal plane shaped detectors deliver powerful new tools for measuring suspended sediments without requiring any assumptions on the underlying particle size distributions or color.

\section{REFERENCES}

Agrawal, Y.C. and H.C. Pottsmith (2000). "Instruments for Particle Size and Settling Velocity Observations in Sediment Transport”, Marine Geology, 168,(1-4), pp 89-114.

Risovic, D. M., (1996). “Fractal dimensions of suspended particles in seawater”. Journal of Colloid and Interface Science, 182, pp 199-203

\section{PUBLICATIONS}

Agrawal, Y.C., and H.C. Pottsmith, 2000: Instruments for Particle Size and Settling Velocity Observations in Sediment Transport, Marine Geology, v168/1-4, pp 89-114.

Agrawal, Y.C. and Traykovski, P., 2001: Particles in the bottom boundary layer, dynamics through events, Jour. Geophys. Res., v106, C5, pp 9533-9542.

Agrawal, Y.C., and H.C. Pottsmith, 2001: A new sensor for mean size and size-independent measurement of suspended sediment concentration (in revision, Marine Geology).

Agrawal, Y.C., and J. Trowbridge, 2002: The Optical Volume Scattering Function: Temporal and Vertical Structure in the Water Column at LEO-15, in Proceedings of Ocean Optics XVI, Santa Fe, NM.

\section{PATENTS}

None. 